\title{
Activated Carbons as Green and Effective Catalysts for Generation of Reactive Radicals in Degradation of Aqueous Phenol
}

\author{
Edy Saputra, ${ }^{a, b}$ Syaifullah Muhammad, ${ }^{a, c}$ Hongqi Sun, ${ }^{a}$ Shaobin Wang*,a \\ 5 Received (in $X X X, X X X) X$ th $X X X X X X X X X 20 X X$, Accepted $X$ th $X X X X X X X X X 20 X X$ \\ DOI: 10.1039/b000000x
}

\begin{abstract}
Several activated carbons (ACs) were used as metal-free catalysts for degradation of a toxic organic compound, phenol, in the presence of different oxidants, $\mathrm{H}_{2} \mathrm{O}_{2}$, peroxydisulfate (PS) and

peroxymonosulfate (PMS). It was found that ACs were effective in heterogeneous activation of PMS to

10 produce sulfate radicals for degradation of phenol, much better than $\mathrm{H}_{2} \mathrm{O}_{2}$ and PS. Particle size of AC

significantly influenced $\mathrm{AC}$ activity, and powder $\mathrm{AC}$ was much effective than granular $\mathrm{AC}$. The complete

phenol removal could be achieved in $15 \mathrm{~min}$ on powder activated carbon (PAC) at the conditions of

$[$ Phenol $]=25 \mathrm{mg} / \mathrm{L},[\mathrm{PAC}]=0.2 \mathrm{~g} / \mathrm{L},[\mathrm{PMS}]=6.5 \mathrm{mmol} / \mathrm{L}$, and $\mathrm{T}=25^{\circ} \mathrm{C}$. It was also found that phenol

degradation was significantly influenced by PMS loading, catalyst loading, phenol concentration and

is temperature. Surface activation of PMS and phenol adsorption played important roles in phenol

degradation. Surface coverage by intermediate adsorption and structural change induced deactivation of

$\mathrm{AC}$ and catalytic activity could be partially recovered by regeneration using calcination.
\end{abstract}

\section{Introduction}

Nowadays, conventional wastewater treatments have been proved 20 to be limited in treating toxic organic compounds. One of the promising methods for degradation of organic pollutants in wastewater is advanced oxidation process (AOP) which can completely degrade organic compounds into carbon dioxide and water. AOPs are based on generation and utilization of reactive 25 species, such as hydroxyl radicals $\left({ }^{\circ} \mathrm{OH}\right)$ and superoxide radicals $\left(\mathrm{O}_{2}{ }^{-} \bullet\right)$ that have a high standard oxidation potential and react nonselectively. ${ }^{1,2}$ Among the AOP methods, heterogeneous catalytic oxidation systems have attracted much attention because of economics and easy recovery of catalysts. ${ }^{3}$ In the heterogeneous 30 systems, the solid catalysts play an important role in achieving a highly efficient oxidation process, not harmful to the environment. Therefore, many studies have concentrated on developing new and effective catalysts, but most of them are metal-based systems, ${ }^{4-6}$ which could induce secondary pollution 35 to water due to metal leaching.

Activated carbons (AC) have been widely used in heterogeneous catalysis either as supports or catalysts due to their porous structure, high specific surface area and pore volume, inexpensiveness and environmentally friendliness. ${ }^{7-10}$ A number

40 of studies have shown that activated carbons are active in the degradation of some dissolved organic pollutants such as 4chlorophenol, trichlorophenol, trichloroethane, methyl tert-butyl ether, methylamines and dimethylamines in the presence of $\mathrm{H}_{2} \mathrm{O}_{2}$. 11-13 It was shown that $\mathrm{AC}$ can promote hydrogen peroxide 45 decomposition through the formation of hydroxyl radicals as shown in the following equations.

$\mathrm{AC}+\mathrm{H}_{2} \mathrm{O}_{2} \rightarrow \mathrm{AC}^{+}+\mathrm{OH}^{-}+{ }^{\bullet} \mathrm{OH}$
${ }_{50} \mathrm{AC}^{+}+\mathrm{H}_{2} \mathrm{O}_{2} \rightarrow \mathrm{AC}+\mathrm{H}^{+}+\mathrm{HO}_{2}^{\bullet}$

Reactions (Equations (1) and (2)) are commonly known as electron-transfer catalysis similar to the Haber-Weiss mechanism, following the Fenton reaction mechanism involving ${ }_{55}$ the oxidized $\left(\mathrm{AC}^{+}\right)$and reduced $(\mathrm{AC})$ catalyst states ${ }^{14}$. However, $\mathrm{AC}$ exhibits much low activity in such a reaction. Recently, sulfate radicals $\left(\mathrm{SO}_{4}^{-\bullet}\right)$ have been proposed as an alternative to hydroxyl radicals for organic degradation due to the higher oxidizing potential $(1.82 \mathrm{~V})$ than that of $\mathrm{H}_{2} \mathrm{O}_{2}(1.76 \mathrm{~V})$. Sulfate 60 radicals can be produced from persulfate (PS) or peroxymonosulfate (PMS). Up to now, activation of PS or PMS was only achieved by metal ions, heat and light, which either requires high energy input or produces metal toxicity. ${ }^{15-17}$ However, few investigations have been reported using ${ }_{65}$ carbonaceous materials for production of sulfate radicals. ${ }^{18} \mathrm{We}$ recently found that graphene could be a good catalyst for PMS activation. ${ }^{19}$ However, graphene is expensive material. Activated carbon is widely available and cheap carbon. Using activated carbon as an alternative to graphene and metal-based catalysts 70 would be not only economic but also environmental benign. In this paper, we report that $\mathrm{AC}$ powder can be a green catalyst in effective activation of PMS, showing an excellent capability of phenol degradation. We investigated the performance of different carbon samples in PMS activation and compared the activity of 75 powder activated carbon in activation of different oxidants, $\mathrm{H}_{2} \mathrm{O}_{2}$, PS and PMS. Several factors influencing the phenol degradation with PMS oxidation were also studied at varying phenol concentrations, AC and PMS loadings and temperatures. The regeneration of $\mathrm{AC}$ was also investigated.

80

Experimental section 


\section{Samples and chemicals}

Two activated carbons produced from coconut shells were obtained in powder and granule from Pancasari Puspa Company, 5 Indonesia. Powder activated carbon (PAC) was used without further treatment. The average particle size was determined to be $30 \mu \mathrm{m}$ by a particle analyzer (Hydro 2000S, Malvern). Granular activated carbon (GAC) was crushed into small particles and seperated according to their sizes into two sections: $60-90 \mu \mathrm{m}$ 10 (GAC-1) and 90-120 $\mu \mathrm{m} \quad(\mathrm{GAC}-2)$. The oxidant, peroxymonosulfate $\left(\mathrm{KHSO}_{5}^{-}, \mathrm{PMS}\right)$ derived from the triple salt, Oxone $\left(2 \mathrm{KHSO}_{5} \cdot \mathrm{KHSO}_{4} \cdot \mathrm{K}_{2} \mathrm{SO}_{4}\right)$, was supplied by SigmaAldrich, Australia. Phenol solution of the required concentrations (i.e. $25,50,75$ and $100 \mathrm{mg} / \mathrm{L}$ ) were prepared from phenic acid ${ }_{15}\left(\mathrm{C}_{6} \mathrm{H}_{5} \mathrm{OH}, 99 \%\right.$ purity, Sigma-Aldrich) by mixing with ultrapure water. Methanol as a quenching reagent $\left(\mathrm{CH}_{3} \mathrm{OH}, 100 \%\right.$ purity) for HPLC analysis was purchased from Perth Scientific, Australia. Sodium nitrite for quenching the reaction for the total organic carbon (TOC) analysis was purchased from Sigma20 Aldrich. $\mathrm{H}_{2} \mathrm{O}_{2}(30 \mathrm{wt} \%)$ and peroxydisulfate (PDS) were also obtained from Sigma-Aldrich.

The AC surface area and pore size measurements were carried out by $\mathrm{N}_{2}$ adsorption using Autosorb-1, Quantachrome (USA). The AC samples were degassed at $100{ }^{\circ} \mathrm{C}$ for $24 \mathrm{~h}$ prior

25 to adsorption analysis. The surface area and pore size distribution were obtained by the Brunauer-Emmett-Teller (BET) and the Barrett-Joyner-Halenda (BJH) methods. Fourier transform infrared spectra (FTIR) were acquired from a Bruker instrument using an ATR mode. X-ray diffraction (XRD) patterns were 30 obtained on a Bruker D8-Advanecd X-ray diffractometer with $\mathrm{Cu}$ $\mathrm{K} \alpha$ radiation $(\lambda=1.5418 \AA)$, at accelerating voltage and current of $40 \mathrm{kV}$ and $40 \mathrm{~mA}$, respectively. Thermogravimetric analysis (TGA) was conducted in air atmosphere at a heating rate of 10 ${ }^{\circ} \mathrm{C} / \mathrm{min}$ on a Perkin-Elmer Diamond TG/DTA thermal analyzer.

Catalytic evaluation of PMS activation for phenol degradation

The catalytic oxidation of phenol was carried out in a $1 \mathrm{~L}$ 40 glass beaker containing $500 \mathrm{~mL}$ at $25,50,75$ and $100 \mathrm{mg} / \mathrm{L}$ of phenolic solutions, which was attached to a stand and dipped in a water bath with a temperature controller. The reaction mixture was stirred constantly at $400 \mathrm{rpm}$ to maintain a homogenous solution. A fixed amount of PMS was added into the solution and 45 allowed to dissolve completely before reaction. Further, a fixed amount of catalysts was added into the reactor to start the oxidation reaction of phenol. The reaction was carried on for 90 minutes and at a fixed interval time, $0.5 \mathrm{~mL}$ of solution sample was taken out from the mixture using a syringe filter of $0.45 \mu \mathrm{m}$ 50 and then mixed with $0.5 \mathrm{~mL}$ methanol to quench the reaction. A few other tests were carried out with different oxidants, hydrogen peroxide and peroxydisulfate (PDS) at the same concentration as PMS. Concentration of phenol was analyzed using a HPLC with a UV detector set at $\lambda=270 \mathrm{~nm}$. The column used was C-18 with 55 mobile phase of $30 \% \mathrm{CH}_{3} \mathrm{CN}$ and $70 \%$ water.

For recycled catalyst tests, two regeneration methods were used. One is simple washing treatment and the other is hightemperature calcination. In general, all the carbon samples were collected by filtration after reaction, washing with water and ${ }_{60}$ drying at $80^{\circ} \mathrm{C}$ overnight for reuse test. Some dried samples were further calcined at $500^{\circ} \mathrm{C}$ in $\mathrm{N}_{2}$ for $1 \mathrm{~h}$.

In order to evaluate the possible effect of inorganic metal components in $\mathrm{AC}$ on catalytic activity, powder $\mathrm{AC}$ was calcined in air at $500{ }^{\circ} \mathrm{C}$ for $2 \mathrm{~h}$ to obtain ash and the ash was tested for ${ }_{65}$ phenol degradation at the above similar conditions.

\section{Results and discussion}

\section{Charcterization of the activated carbons}

The BET surface area, pore volume and pore radius for the 70 carbons are shown in Table 1 . It can be observed that there is a significant difference in the surface area and pore volume. PAC has higher surface area $\left(824.7 \mathrm{~m}^{2} / \mathrm{g}\right)$, pore volume $\left(0.470 \mathrm{~cm}^{3} / \mathrm{g}\right)$, and pore radius $(22.8 \AA)$ than others. For both granular $\mathrm{AC}$ particles (GAC-1 and GAC-2), GAC-1 has slightly higher surface 75 area, pore volume and pore radius due to smaller particle size. XRD indicates amorphous structure of PAC without other crystallites (Fig.S1) and a thermogravimetric analysis (TGA) shows PAC contains $93 \%$ of carbon (Fig.S2).

80 Table 1. Surface area, pore volume and pore radius of activated carbons.

\begin{tabular}{lllll}
\hline Catalyst & $\begin{array}{l}\mathrm{S}_{\mathrm{BET}} \\
\left(\mathrm{m}^{2} / \mathrm{g}\right)\end{array}$ & $\begin{array}{l}\mathrm{V} \\
\left(\mathrm{cm}^{3} / \mathrm{g}\right)\end{array}$ & $\begin{array}{l}\text { Pore radius } \\
(\AA)\end{array}$ & Conv/S \\
\hline PAC & 824.7 & 0.470 & 22.8 & 0.103 \\
$\mathrm{GAC}-1$ & 586.9 & 0.250 & 17.0 & 0.051 \\
$\mathrm{GAC}-2$ & 560.9 & 0.236 & 16.9 & 0.052 \\
\hline
\end{tabular}

\section{Preliminary study of phenol oxidation using AC catalysts}

Fig. 1 shows the preliminary tests of adsorption and catalytic 85 oxidation of phenol using different AC samples. It is generally accepted that $\mathrm{AC}$ has a good adsorption capacity. As can be seen, all ACs were able to adsorb phenol with different capacities. Both GAC-1 and GAC-2 showed low adsorption of phenol at less than $20 \%$ in 90 min. While PAC presented double phenol adsorption 90 efficiency in $90 \mathrm{~min}$ at $50 \%$, which can be ascribed to higher surface area of PAC. Inset of Fig. 1 displayed oxidation of phenol by PMS without AC and negligible change in phenol concentration was observed. Less than $3 \%$ in phenol concentration reduction was found after 90 min, suggesting that 95 PMS itself could not produce sulfate radical to induce significant oxidation of phenol. In oxidation tests, PAC with PMS in the heterogeneous system could degrade phenol up to $85 \%$ in $90 \mathrm{~min}$. Meanwhile, GAC-1 and GAC-2 could only reach around 30 and $25 \%$ phenol removal, respectively, at the same period.

100 The experimental results showed that surface area of ACs influenced significantly phenol degradation. Based on surface area, phenol conversions for three ACs were normalized (Table 1) and it is seen that PAC presented higher activity than GACs. This suggests particle size also affect the catalytic activity. ${ }_{105}$ Characterization shows that the three AC samples have different particle sizes and surface areas. PAC has the highest surface area and lowest particle size. Phenol removal is dependent on adsorption and produced sulfate radicals $\left(\mathrm{SO}_{4}{ }^{-\bullet}\right.$ and $\left.\mathrm{SO}_{5}{ }^{-\bullet}\right)$. At the same concentration of PMS, sulfate radical concentration 110 produced will depend on active sites on surface area and edges of carbon catalysts. Thus, the catalysts with a high surface area can provide more active sites for adsorption and more sulfate radicals, resulting in high phenol degradation. Meanwhile, small particle size of AC provides more edges, making the contact more 15 frequently between $\mathrm{AC}$ and reactant, thus enhancing reaction rate or efficiency. In addition, TOC removal in PAC/PMS system was also examined and the result showed that about $75 \%$ phenol removal was obtained within $90 \mathrm{~min}$. 


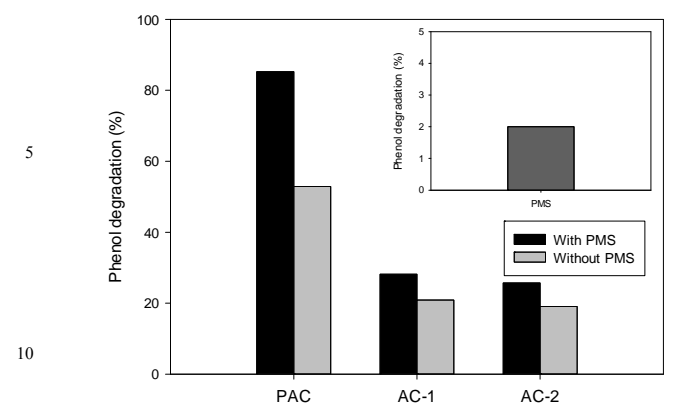

Fig. 1 Prelimenary study of phenol at different size of catalyst. Reaction condition: $[$ Phenol] $=50 \mathrm{mg} / \mathrm{L}$, catalyst $=0.2 \mathrm{~g} / \mathrm{L}, \mathrm{PMS}$ $=6.5 \mathrm{mmol} / \mathrm{L}$, and $\mathrm{T}=25^{\circ} \mathrm{C}$.

15 Previously, Anipsitakis and Dionysiou ${ }^{20}$ have tested several metal ions, $\mathrm{Ag}(\mathrm{I}), \mathrm{Ce}(\mathrm{III}), \mathrm{Co}(\mathrm{II}), \mathrm{Fe}(\mathrm{II}), \mathrm{Fe}(\mathrm{III}), \mathrm{Mn}(\mathrm{II}), \mathrm{Ni}(\mathrm{II})$, $\mathrm{Ru}(\mathrm{III})$, and V(III), for homogeneous activation of PMS and found that $\mathrm{Co}(\mathrm{II}), \mathrm{Ru}(\mathrm{III})$, and $\mathrm{Fe}(\mathrm{II})$ interact with PMS to produce freely diffusible sulfate radicals for reaction. In this 20 investigation, PAC was calcined to obtain its ash component and then tested under the same conditions in PMS activation for phenol degradation. As shown in Fig.2, the ash did not produce strong phenol degradation with only $4 \%$ phenol removal in 90 min. Some other investigations have shown that solid metal 25 oxides, $\mathrm{TiO}_{2}, \mathrm{SiO}_{2}, \mathrm{Al}_{2} \mathrm{O}_{3}$, zeolites, fly ash and red mud could not activate PMS. ${ }^{15}, 21,22$ Thus, the inorganic impurities as metal oxides in activated carbon can not induce PMS activation and carbon is the active catalyst. The reaction mechanism for heterogeneous phenol oxidation can be proposed as follows.

30

$\mathrm{AC}+\mathrm{HSO}_{5}^{-} \rightarrow \mathrm{AC}^{+}+\mathrm{OH}^{-}+\mathrm{SO}_{4}^{-\bullet}$

$\mathrm{AC}^{+}+\mathrm{HSO}_{5}^{-} \rightarrow \mathrm{AC}+\mathrm{H}^{+}+\mathrm{SO}_{5}^{-\bullet}$

$\mathrm{SO}_{4}^{-\bullet}+\mathrm{H}_{2} \mathrm{O} \rightarrow \mathrm{SO}_{4}{ }^{2-}+{ }^{\bullet} \mathrm{OH}+\mathrm{H}^{+}$

$\mathrm{SO}_{4}^{-\bullet}+\mathrm{C}_{6} \mathrm{H}_{5} \mathrm{OH} \rightarrow$ several steps $\rightarrow \mathrm{CO}_{2}+\mathrm{H}_{2} \mathrm{O}+\mathrm{SO}_{4}^{2-}$

35 Several investigations have been reported in activated carbon catalysts for organic decomposition using different oxidants. Santos et al. ${ }^{23}$ studied the modified activated carbon (100-300 $\mu \mathrm{m})$ for heteregoneous activation of $\mathrm{H}_{2} \mathrm{O}_{2}$ to generate hydroxyl radicals targeting at the decolororization of reactive red 241.

40 Modified activated carbon could achieve $65 \%$ color removal at reactive red 241 concentration of $50 \mathrm{mg} / \mathrm{L}$ within $150 \mathrm{~min}$. They also found that the catalytic activity was influenced significantly by $\mathrm{pH}$. Yao et al. ${ }^{24}$ used reduced graphene oxide (rGO) nanoparticle with peroxymonosulfate for phenol degradation at ${ }_{45} 20 \mathrm{mg} / \mathrm{L}$. rGO could achieve $20 \%$ phenol degradation within 60 min. Shukla et al. ${ }^{8}$ studied activated carbon with peroxymonosulfate for phenol degradation at $25 \mathrm{mg} / \mathrm{L}$. The activated carbon could achieve $48 \%$ phenol degradation within 60 min. Therefore, it is seen that PAC with peroxymonosulfate in

${ }_{50}$ this investigation presented higher activity in phenol degradation than other activated carbons and rGO.

\section{Effect of reaction parameters on phenol degradation}

Fig. 2 shows a comparison of phenol oxidation in PAC with different oxidants (PMS, PDS, and $\mathrm{H}_{2} \mathrm{O}_{2}$ ). As can be seen, PAC 55 could activate all three oxidants although the removal efficiencies of phenol were different. PAC with peroxymonosulfate resulted in complete degradation of phenol in less than $20 \mathrm{~min}$. PAC with PDS could achieve 100\% removal of phenol in 90 min while PAC with $\mathrm{H}_{2} \mathrm{O}_{2}$ could achieve only $50 \%$ phenol removal in 90

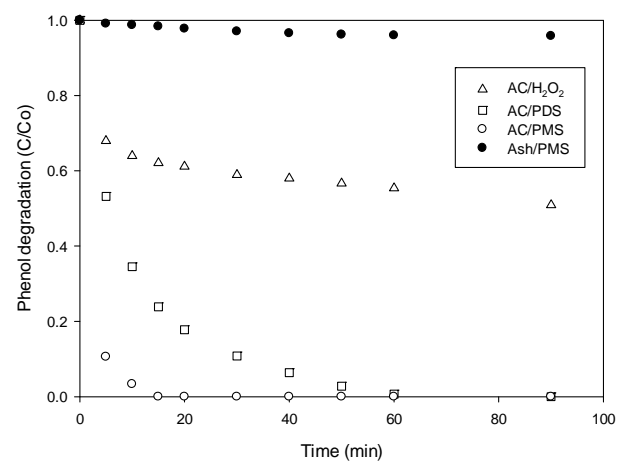

Fig. 2 Phenol trasfomation by the interaction of PAC and three different oxidants. Reaction condition: [Phenol] $=25 \mathrm{mg} / \mathrm{L}$, catalyst $=0.2 \mathrm{~g} / \mathrm{L}$, oxidant $=6.5 \mathrm{mmol} / \mathrm{L}$, and $\mathrm{T}=25^{\circ} \mathrm{C}$.

65

min. The experimental results indicate that the catalytic activity strongly depends on the oxidation potential of oxidants. The catalytic activity shows an order of PAC/ $\mathrm{H}_{2} \mathrm{O}_{2}<$ PAC/PDS $<$ $\mathrm{PAC} / \mathrm{PMS}$ in phenol degradation. Anipsitakis and Dionysiou ${ }^{20}$ 70 studied homogeneous activation of PMS, PDS and $\mathrm{H}_{2} \mathrm{O}_{2}$ with some transition metal ions for 2,4-DCP oxidation. It was reported that $\mathrm{M}^{2+} / \mathrm{PMS}$ showed the highest 2,4-DCP removal, followed by $\mathrm{M}^{2+} / \mathrm{PDS}$ and $\mathrm{M}^{2+} / \mathrm{H}_{2} \mathrm{O}_{2}$. Thus, it would be expected a similar reaction rate for heterogeneous systems in this investigation.

75 Fig. 3 presents the variation of normalized phenol concentration as a function of PMS concentration in the solution. As can be seen, the degradation of phenol by PAC/PMS depended on initial concentration of PMS. Higher concentration of PMS resulted in higher removal efficiency of phenol. The 80 complete phenol degradation could be achieved at $6.5 \mathrm{mmol}$ PMS loading in $15 \mathrm{~min}$, while in the same duration at PMS concentrations of 5.5, 2.6, and $1.3 \mathrm{mmol}$, phenol removal efficiency were obtained at 98,94 , and $87 \%$, respectively.

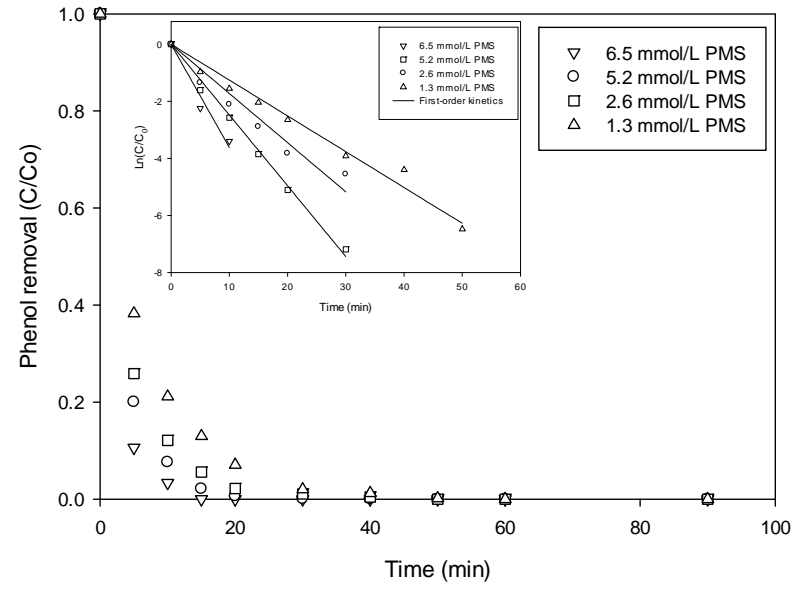

Fig. 3 Effect of PMS concentration on phenol removal. Reaction condition: $[$ Phenol $]=25 \mathrm{mg} / \mathrm{L}$, catalyst $=0.2 \mathrm{~g} / \mathrm{L}$ and $\mathrm{T}=25^{\circ} \mathrm{C}$.

A general pseudo first order kinetics for phenol degradation 90 was employed to estimate the kinetic rates, as shown in equation below.

$\operatorname{Ln}\left(\mathrm{C} / \mathrm{C}_{0}\right)=-\mathrm{k} \times \mathrm{t}$ 
Where $\mathrm{k}$ is the apparent first order rate constant of phenol removal, $\mathrm{C}$ is the concentration of phenol at various time $(\mathrm{t}) . \mathrm{C}_{\mathrm{o}}$ is the initial phenol concentration. Using this model, $\ln \left(\mathrm{C} / \mathrm{C}_{\mathrm{o}}\right)$ versus time $(\mathrm{t})$ produced straight lines as shown in Fig. 3 (inset). 5 The rate constants at varying PMS concentrations are shown in Table S1. As seen, rate constant will decrease as the concentration of PMS decreases.

It is believed that phenol degradation efficiency also depended on initial concentration of phenol in solution. Fig. S3 10 shows phenol degradation at various concentrations between 25 and $100 \mathrm{mg} / \mathrm{L}$. At high phenol concentration, removal efficiency tended to decrease. At $25 \mathrm{mg} / \mathrm{L}$, phenol removal was very fast and achieved $100 \%$ degradation within $15 \mathrm{~min}$, whereas at phenol concentrations of 50,75 and $100 \mathrm{mg} / \mathrm{L}$, the degradation rate was 15 slower and phenol removal would achieve at only 85,62 , and $42 \%$, respectively, in 90 min.

The effect of PAC loading in solution on phenol degradation is shown in Fig. S4. An increase in PAC amount in the solution increased the phenol degradation efficiency. A complete removal 20 of phenol could be reached wihtin $15 \mathrm{~min}$ at $0.2 \mathrm{~g} / \mathrm{L} \mathrm{PAC}$ loading. Whereas $70.5 \%$ and $40 \%$ removals could be reached at PAC loading of 0.1 and $0.06 \mathrm{~g} / \mathrm{L}$, respectively. For phenol degradation, increased catalyst loading would enhance adsorption and provided additional sites for generation of active sulfate 25 radicals, thus enhancing phenol degradation.

Furthermore, temperature is also a variable influencing catalyst activity and phenol degradation. Fig. 4 shows the reduction of phenol concentration versus time at various temperatures of $25-45{ }^{\circ} \mathrm{C}$. As can be seen that the rate of 30 reaction would increase with incresed temperature. At temperature of $25{ }^{\circ} \mathrm{C}$, phenol removal would reach $85 \%$ at 50 $\mathrm{mg} / \mathrm{L}$ in $90 \mathrm{~min}$. While in the same duration and phenol concentration at temperatures of 35 and $45{ }^{\circ} \mathrm{C}$, phenol removal efficiency were obtained at 91 and $95 \%$, respectively. Using the

35 first order kinetic rate constant, the activation energy for this heteregeneous phenol decomposition was found to be 17.6 $\mathrm{kJ} / \mathrm{mol}$. It should be noted that phenol degradation in PAC-PMS system would be ascribed to adsorption and oxidation. In this study, it would be difficult to distinguish the contribution of each 40 part (adsorption and oxidation). Thus, the activation energy value obtained would refer to the combined processes. Previously, we have investigated several heterogeneous carbon supported $\mathrm{Co}$ and $\mathrm{Ru}$ catalysts, such as $\mathrm{Co} / \mathrm{AC}, \mathrm{Co} / \mathrm{CX}$ (carbon-xerogel) and $\mathrm{RuO}_{2} / \mathrm{AC}$, in activation of PMS for phenol degradation and the 45 activation energies obtained are presented in Table 2. As can be seen, that PAC presented lower activation energy than $\mathrm{AC}$ supported $\mathrm{Co}$ and $\mathrm{Ru}$ catalysts.

50

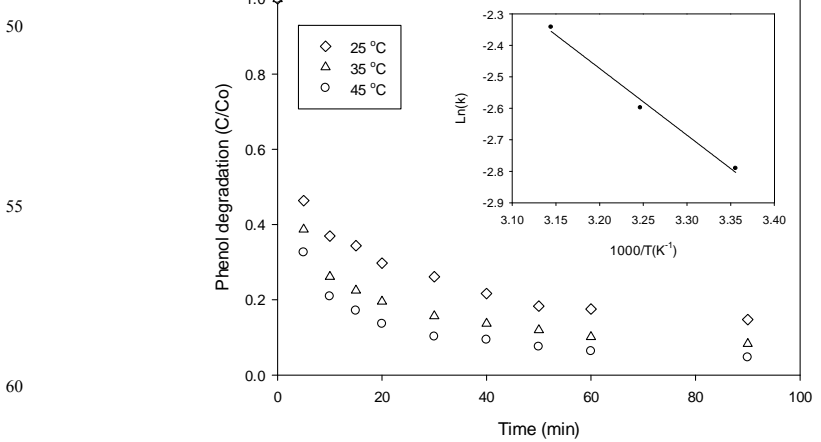

Fig. 4 Effect of temperature on phenol removal. Reaction condition: $[$ Phenol $]=50 \mathrm{mg} / \mathrm{L}$, catalyst $=0.2 \mathrm{~g} / \mathrm{L}$, and $\mathrm{PMS}=6.5$ ${ }_{65} \mathrm{mmol} / \mathrm{L}$.
Table 2. Activation of heterogeneous catalysts with PMS for phenol degradation.

\begin{tabular}{lll}
\hline Catalyst & Activation energy $(\mathrm{kJ} / \mathrm{mol})$ & Reference \\
\hline $\mathrm{Co} / \mathrm{AC}$ & 59.7 & 8 \\
$\mathrm{Co} / \mathrm{CX}-1$ & 48.3 & 25 \\
$\mathrm{Co} / \mathrm{CX}-\mathrm{G}$ & 62.9 & 25 \\
$\mathrm{RuO} / \mathrm{AC}$ & 61.4 & 26 \\
$\mathrm{Co} / \mathrm{rGO}$ & 26.5 & 27 \\
$\mathrm{rGO}$ & 84.9 & 19 \\
$\mathrm{PAC}$ & 17.6 & This work \\
\hline
\end{tabular}

\section{${ }_{70}$ Reactivity of spent PAC catalyst and reusability}

Fig. 5 shows the catalytic activity of recycled PAC for phenol degradation. As can be seen, the catalytic activity significantly reduced in the second use, suggesting deactivation of the catalyst. In the second use, phenol removal was $34 \%$ at 15 min compared 75 with $100 \%$ in the first use. Furthermore, in PAC second use after thermal treatment at $500{ }^{\circ} \mathrm{C}$ for $1 \mathrm{~h}$, it appears that the catalyst activity increased again although not as the same as the first use and $62 \%$ phenol degradation could be achieved at $15 \mathrm{~min}$.

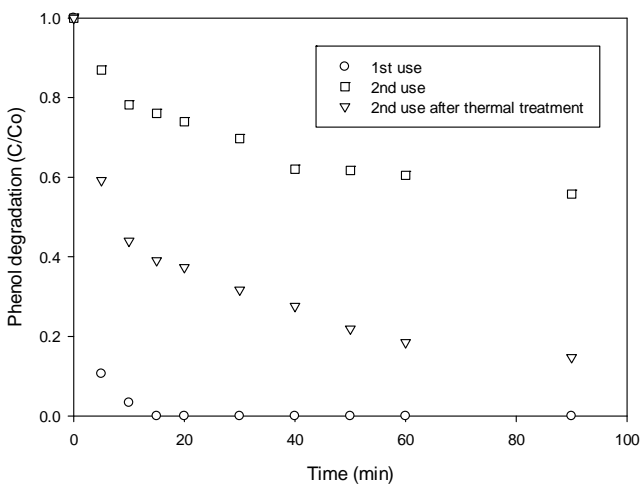

Fig. 5 phenol removal in tests of recycled PAC catalyst. Reaction condition: $[$ Phenol $]=25 \mathrm{mg} / \mathrm{L}$, catalyst $=0.2 \mathrm{~g} / \mathrm{L}$, and $\mathrm{PMS}=6.5$ $90 \mathrm{mmol} / \mathrm{L}$.

\section{Role of powder activated carbon catalyst in phenol degradation}

${ }_{95}$ Fig.6 shows FT-IR spectra of fresh PAC, after adsorption of phenol and PMS as well as after reaction. For fresh PAC, two strong absorption bands were observed at 1120 and $1560 \mathrm{~cm}^{-1}$, respectively, which are corresponding to $\mathrm{C}-\mathrm{O}$ and $\mathrm{C}=\mathrm{O}$ functional groups, respectively. After phenol adsorption, the absorption 100 band at $1120 \mathrm{~cm}^{-1}$ was shifted to $1065 \mathrm{~cm}^{-1}$, due to the strong interaction of adsorbed phenol with carbon. Meanwhile, two weak absorption peaks were appeared at 2895 and $2980 \mathrm{~cm}^{-1}$, which are referred to $\mathrm{C}-\mathrm{H}$ vibration. For PAC-PMS system, two more strong absorption bands could be observed. One is at 1192 $105 \mathrm{~cm}^{-1}$, which is corresponding to $\mathrm{S}-\mathrm{O}$ stretching vibration ${ }^{28,29}$ and the other is carboxylic $\mathrm{C}=\mathrm{O}$ absorption at $1720 \mathrm{~cm}^{-1}$. In addition, the band at $3200-3400 \mathrm{~cm}^{-1}$ became stronger, which is due to $\mathrm{OH}$ stretching of $\mathrm{HSO}_{4}$ group. These changes in FT-IR suggest the activation of PMS by carbon for sulfate radical generation. After 110 reaction with PMS and phenol, FT-IR showed all the absorption bands related to phenol adsorption and PMS activation. However, the band for $\mathrm{C}-\mathrm{O}$ was shifted to $1080 \mathrm{~cm}^{-1}$, due to the 
decomposition of phenol and weaker adsorption. In addition, the peak at $1720 \mathrm{~cm}^{-1}$ is much weaker, due to the consumption of sulfate radical in phenol oxidation.

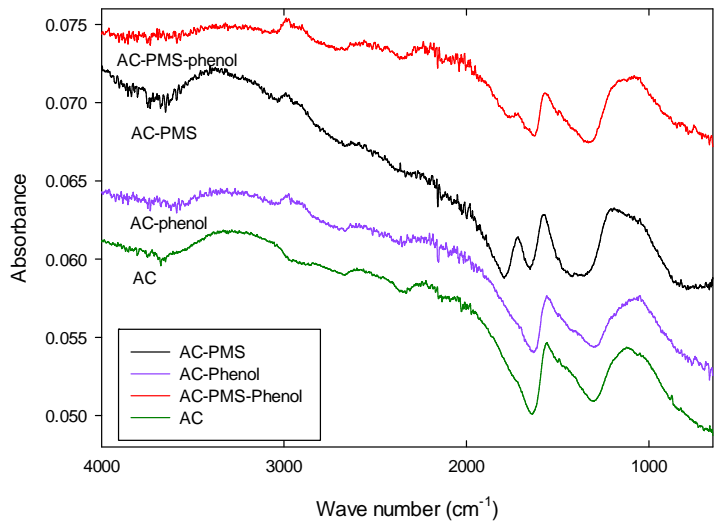

5 Fig.6 FT-IR spectra of PAC before and after adsorption and reaction.

During catalytic oxidation of toxic organics, powder activated carbon primarily acted as an adsorbent for phenol, as shown in ${ }_{10}$ Fig.1. This may increase the probability of a reaction between peroxymonosulfate and phenol. Meanwhile, powder activated carbon catalyses the decomposition of peroxymonosulfate into free radicals, such as sulfate radicals. These sulfate radicals are very active in oxidation reactions on carbon surface and in the 15 aqueous phase. Then, sulfate radicals and phenol can react on the catalyst surface to produce simple molecular compounds including $\mathrm{CO}_{2}$ and $\mathrm{H}_{2} \mathrm{O}$ (Eqs.3-6). Although the peroxymonosulfate decomposition mechanism is not completely understood, the electron transfer from the surface of powder 20 activated carbon have been suggested to take place during the reaction. According to the mechanism, the reaction might be initiated by a reducing site transferring an electron to peroxymonosulfate to produce sulfate radicals (Eq.3). MorenoCastilla et al. ${ }^{30}$ investigated activated carbon cloth with $\mathrm{H}_{2} \mathrm{O}_{2}$ for 25 the removal of amitrole from aqueous solution. The studies have suggested that basic sites on carbon surface promote $\mathrm{H}_{2} \mathrm{O}_{2}$ decomposition into hydroxyl and perydroxyl radicals, thereby enhanching the oxidation of organic compounds in liquid. They also found that the surface sites may be delocalized $\pi$ electrons 30 from the graphene layers $(\mathrm{C}-\pi)$, which transfering electron according to the mechanism as follows:

$$
\begin{aligned}
& \mathrm{C}-\pi+\mathrm{H}_{2} \mathrm{O}_{2} \rightarrow \mathrm{C}-\pi^{+}+\mathrm{OH}^{-}+{ }^{\bullet} \mathrm{OH} \\
& \mathrm{C}-\pi^{+}+\mathrm{H}_{2} \mathrm{O}_{2} \rightarrow \mathrm{C}-\pi+\mathrm{H}^{+}+\mathrm{HO}_{2}^{\bullet}
\end{aligned}
$$

35

Thus, the current study using peroxymonosulfate as an oxidant will be in similar consequences. The reaction initiated by the activation of peroxymonosulfate by a reducing site in a Fenton like reaction to produce a $\mathrm{SO}_{4}^{-*}$ radical. This sulfate 40 radical can then react with phenol as shown in Scheme 1.

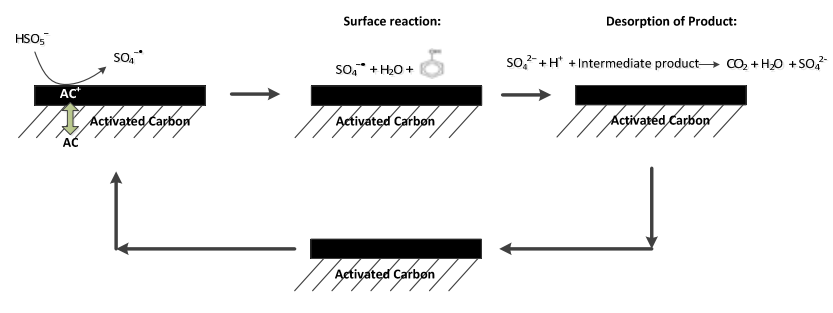

Scheme 1 Mechanism for phenol removal during powder 45 activated carbon (PAC) activation of peroxymonosulfate.

\section{Conclusions}

PAC can be a cheap, green and effective catalyst in activation of $\mathrm{H}_{2} \mathrm{O}_{2}$, PDS and PMS to produce hydroxyl and sulphate radicals for phenol degradation. PAC exhibited higher activity than GAC

50 and higher activity in PMS activation. Phenol degradation can be achieved in a short time with AC/PMS. High PAC and PMS concentrations in solution will make high phenol degradation efficiency. Phenol degradation followed the first-order kinetics and activation energy of the catalyst was obtained as $17.6 \mathrm{~kJ} / \mathrm{mol}$.

${ }_{55}$ Surface reaction between PAC and PMS generated sulphate radicals for phenol decomposition. Adsorption of intermediates and structural change resulted in deactivation of PAC and the regeneration by calcination could partially recover the catalytic activity.

\section{Acknowledgement}

This project was partially supported by the Australian Research Council under project No: DP130101319

\section{${ }_{65}$ Notes and references}

a Department of Chemical Engineering, Curtin University, GPO Box U1987, Perth, WA 6845, Australia. Fax: 618 92662681; Tel: 618 92663776; E-mail: shaobin.wang@curtin.edu.au

${ }^{b}$ Department of Chemical Engineering, Riau University, Pekanbaru 70 28293, Indonesia

${ }^{\mathrm{c}}$ Department of Chemical Engineering, Syiah Kuala University, Banda

Aceh, Indonesia

$\dagger$ Electronic Supplementary Information (ESI) available: [XRD, TGA of 75 powder activated carbon, effect of phenol concentration and effect of catalyst loading and rate constant]. See DOI: 10.1039/b000000x/

1. C.-P. Huang and Y.-H. Huang, Appl. Catal. A-Gen, 2009, 357, 135$80 \quad 141$.

2. G. Calleja, J. A. Melero, F. Martínez and R. Molina, Water Res. 2005, 39, 1741-1750.

3. K. Fajerwerg and H. Debellefontaine, Appl. Catal. B-Environ. 1996, 10, L229-L235.

85 4. S. Imamura, A. Doi and S. Ishida, Ind. Eng. Chem. Prod. Res. Devel., 1985, 24, 75-80.

5. P. M. Alvarez, D. McLurgh and P. Plucinski, Ind. Eng. Chem. Res 2002, 41, 2153-2158.

6. P. Baldrian, V. Merhautová, J. Gabriel, F. Nerud, P. Stopka, M. 90 Hrubý and M. J. Benes, Appl. Catal. B-Environ. 2006, 66, 258-264.

7. F. Stüber, J. Font, A. Fortuny, C. Bengoa, A. Eftaxias and A. Fabregat, Top. Catal. 2005, 33, 3-50.

8. P. R. Shukla, S. Wang, H. Sun, H. M. Ang and M. Tadé, Appl. Catal. B-Environ. 2010, 100, 529-534.

9. P. C. C. Faria, J. J. M. Órão and M. F. R. Pereira, Appl. Catal. BEnviron. 2008, 79, 237-243.

10. E. Auer, A. Freund, J. Pietsch and T. Tacke, Appl. Catal. A-Gen, 1998, 173, 259-271

100 11. C. Aguilar, R. García, G. Soto-Garrido and R. Arraigada, Top. Catal. 2005, 33, 201-206.

12. H.-H. Huang, M.-C. Lu, J.-N. Chen and C.-T. Lee, Chemosphere, 2003, 51, 935-943.

13. A. Georgi and F.-D. Kopinke, Appl. Catal. B-Environ. 2005, 58, 9-

14. M. Kimura and I. Miyamoto, Bull. Chem. Soc. Jpn. 1994, 67, 2357 2360 
15. E. Saputra, M. S., H. Sun, H. M. Ang, M. O. Tadé and S. Wang, Catal. Today, 2012, 190, 68-72.

16. K.-C. Huang, R. A. Couttenye and G. E. Hoag, Chemosphere, 2002, 49, 413-420.

5 17. P. R. Shukla, S. Wang, H. M. Ang and M. O. Tadé, Sep. Purif. Technol. 2010, 70, 338-344.

18. S. Yang, X. Yang, X. Shao, R. Niu and L. Wang, J. Hazard. Mater. 2011, 186, 659-666.

19. H. Sun, S. Liu, G. Zhou, H. M. Ang, M. O. Tade and S. Wang, ACS

10 Appl. Mater. Interf. 2012, 4, 5466-5471.

20. G. P. Anipsitakis and D. D. Dionysiou, Environ. Sci. Technol. 2004, 38, 3705-3712.

21. H. Sun, H. Liang, G. Zhou and S. Wang, J. Colloid Interf. Sci. 2013, 394, 394-400.

15 22. P. Shukla, S. Wang, K. Singh, H. M. Ang and M. O. Tadé, Appl. Catal. B-Environ. 2010, 99, 163-169.

23. V. P. Santos, M. F. R. Pereira, P. C. C. Faria and J. J. M. Órfão, J. Hazard. Mater. 2009, 162, 736-742.

24. Y. Yao, Z. Yang, D. Zhang, W. Peng, H. Sun and S. Wang, Ind. Eng. 20 Chem. Res. 2012, 51, 6044-6051.

25. H. Sun, H. Tian, Y. Hardjono, C. E. Buckley and S. Wang, Catal. Today, 2012, 186, 63-68.

26. S. Muhammad, P. R. Shukla, M. O. Tadé and S. Wang, J. Hazard. Mater. 2012, 215-216, 183-190.

25 27. Y. Yao, Z. Yang, H. Sun and S. Wang, Ind. Eng. Chem. Res. 2012, 51, 14958-14965.

28. S. J. Hug, J. Colloid Interf. Sci. 1997, 188, 415-422.

29. M. Bukleski, V. Ivanovski and V. M. Petruševski, Vibrational Spectroscopy, 2011, 57, 15-22.

30 30. C. Moreno-Castilla, M. A. Fontecha-Cámara, M. A. Álvarez-Merino, M. V. López-Ramón and F. Carrasco-Marín, Adsorption, 2011, 17, 413-419. 